blood straight from a donor and therefore insufficiently tested. "Warm blood" is demanded not only for neonatal exchange transfusion but for practically all cases of emergency transfusion. Its advocates prove uniformly unable to refer to controlled studies suggesting an improved outcome in recipients of "warm blood" compared with those given fully tested stored blood. Before more and more clinicians switch over to this dubious pre-first-world-war procedure, apparently for irrational reasons, careful prospective investigations in this field are urgently needed.

German Red Cross Blood Transfusion
Service,

Münster, West Germany

\section{Cockles of the heart}

SIR,-The origin of the expression "warming the cockles of the heart" (12 November, p 1271) is simple: the left atrium or cockle is in close relationship to the oesophagus and when hot liquid passes down the gullet the cockle is warmed. The expression is derived from a common-sense interpretation of anatomy. Using the plural and including the right atrium is allowable poetic licence; cockle (singular) sounds odd.

RUTH PORTER

Ciba Foundation,
London W1

\section{Indomethacin in pleurisy}

SIR,-Dr K P Goldman's assertion that there is no previous report on the use of indomethacin for relieving pleuritic pain (19 November, $p$ 1353) is inaccurate. Without undertaking an exhaustive literature search I can cite at least two clinical reports documenting successful therapy of acute pleuritic pain with indomethacin.

One report ${ }^{1}$ indicates that the drug be administered in substantial amounts, $100 \mathrm{mg}$ every two hours for 4-6 doses. Relief is obtained shortly, usually after the first few days. The drug can then be given in the usual maintenance dosage of $25-50 \mathrm{mg}$ four times a day. Except for minor cases of nausea and euphoria no serious adverse reactions were noted with this regimen even after two years of use.

The second report ${ }^{2}$ shows that in a doubleblind study satisfactory analgesia was experienced by $84 \%$ of 51 patients with acute, severe pleuritic chest pain who received a single suppository containing $100 \mathrm{mg}$ of indomethacin compared with $35 \%$ given placebo. Relief of pain started within $30 \mathrm{~min}$ in $52 \%$ and within $60 \mathrm{~min}$ in $85 \%$ of indomethacin responders, reaching a maximal effect within $90 \mathrm{~min}$ in $67 \%$ of the patients. Significant improvements were noted in respect of mechanical lung function, respiratory rate, and the ability to cough effectively in patients experiencing analgesia due to indomethacin. Four of the 25 patients receiving the drug experienced mild to moderate dizziness and two other patients complained of mild nausea.

According to a study by Halt et $a l^{3}$ therapeutic serum levels of indomethacin are reached sooner after rectal than after oral administration of the same dose. In addition, rectal administration of indomethacin has the advantage of not causing gastrointestinal distress and is a useful alternative when oral use is contraindicated in patients with dyspepsia or peptic ulceration. ${ }^{4}$
Although the exact mechanism of indomethacin-induced analgesia in pleuritic pain is not known, the effect might be related to the drug's powerful anti-inflammatory properties, ${ }^{5}$ which allow it to interfere in some manner with pain-producing chemical mediators.

JARA S GHOSH

Ardmore,
Pennsylvania, USA

Baron, B R, New England fournal of Medicine, 1968, 278, 1291 .

Sacks, P V, and Kanarek, D, American Review of

${ }^{3}$ Holt, L P J, and Hawkins, C F, British Medical Fournal, 1965, 1, 1354

Kerckhoffs, H P M, and Huizinga, T, Pharmaceutisch Weekblad, 1967, 102, 1183.

Winter, C A, Risley, E A, and Nuss, G W, fournal of Pharmacology and Experimental Therapeutics, 1963, 141, 369

Roszkowski, A P, et al, fournal of Pharmacology and Experimental Therapeutics, $1971,179,114$.

America, 1968, 52, 3 .

\section{Cooking the turkey}

SIR,-Scrutator's indignation (7 January, p 57) about the Departmental advice on the cooking of turkeys is misplaced. In 20 years' experience of the control of infectious disease by far the great majority of outbreaks of food poisoning that $\mathrm{I}$ have dealt with have been the result of badly prepared, cooked, or served large turkeys, and it is clear that many catering managers still need to be reminded of good practice in this field.

D G H Patey

Bury St Edmunds Health

District,
Bury St Edmunds, Suffolk

\section{Initiation of once-daily pindolol treatment}

SIR,-An increasing number of patients with moderate hypertension are now treated with beta-blockers in a once-daily regimen. In Sweden pindolol, metoprolol, and propranolol are now officially approved for administration in this way. Usually the optimum dose of the beta-blocker is reached by a gradual titration. ${ }^{12}$ For practical reasons it is of course an advantage if the optimum dose can be given once daily from the start of the treatment. For pindolol several studies have indicated the optimum once-daily dose to be $10-15 \mathrm{mg}^{3}$ Against this background a study has been performed with the aim of comparing the tolerability of $15 \mathrm{mg}$ pindolol given once daily and $5 \mathrm{mg}$ administered three times daily.

Twenty ambulatory patients, 15 men and five women of mean age 42 , with moderate hypertension, previously untreated, entered the study. The criterion for acceptance was a diastolic blood pressure of $\geqslant 105 \mathrm{~mm} \mathrm{Hg}$ on at least two different occasions maintained during an initial placebo period of four weeks. The blood pressure was measured in the morning, always before the first tablet intake

Effects of pindolol treatment $15 \mathrm{mg}$ once daily (group $A$ ) and $5 \mathrm{mg}$ thrice daily (group B) on mean blood pressure and pulse rate

\begin{tabular}{|c|c|c|c|c|c|}
\hline & & \multicolumn{2}{|c|}{ Group A } & \multicolumn{2}{|c|}{ Group B } \\
\hline & & $\begin{array}{c}\text { Blood pressure } \\
(\mathrm{mm} \mathrm{Hg})\end{array}$ & $\begin{array}{c}\text { Pulse rate } \\
\text { (beats/min) }\end{array}$ & $\begin{array}{c}\text { Blood pressure } \\
(\mathrm{mm} \mathrm{Hg})\end{array}$ & $\begin{array}{l}\text { Pulse rate } \\
\text { (beats/min) }\end{array}$ \\
\hline $\begin{array}{l}\text { After } 4 \text { weeks' placebo } \\
\text { After } 4 \text { weeks' active treatment } \\
\text { After } 12 \text { weeks' active treatment }\end{array}$ & $\begin{array}{ll}\cdots & \cdots \\
\cdots & \cdots\end{array}$ & $\begin{array}{l}164 / 107 \\
147 / 93 \\
141 / 85\end{array}$ & $\begin{array}{l}74 \\
69 \\
71\end{array}$ & $\begin{array}{l}174 / 108 \\
149 / 94 \\
147 / 88\end{array}$ & $\begin{array}{l}76 \\
70 \\
69\end{array}$ \\
\hline
\end{tabular}

that day. The patients were divided at random into two different groups, group A being given $15 \mathrm{mg}$ once daily and group $B$ receiving $5 \mathrm{mg}$ three times daily. Double-blind conditions were obtained by using blister-packages.

The mean supine blood pressure and heart rate at the end of the placebo period and after four and 12 weeks of active treatment for the two groups are shown in the table below. There was a significant reduction of the blood pressure after four weeks' active treatment for both groups. There was no difference in the pressure reduction between the groups after either four or 12 weeks' therapy. In three cases side effects were recorded. One woman taking $5 \mathrm{mg}$ thrice daily discontinued treatment after one week owing to fatigue and vertigo; in another case the patient complained of sleep disturbances but continued therapy. One patient on $15 \mathrm{mg}$ once daily noticed vertigo two hours after the tablet intake.

In summary, a gradual titration of pindolol in the once-daily regimen seems unnecessary and the optimum dose can be given directly without increasing the risk of side effects. Thus a simpler regimen can be obtained which may help to keep the patient on the treatment.

GÖRAN FRITHZ

Department of Medicine, Central Hospital,

${ }^{1}$ Frithz, G, Upsala fournal of Medical Science, 1976,
81,151 .
${ }^{2}$ Frithz, G, Acta Medica Scandinavica, 1977, suppl.
$606, \mathrm{p} 77$.
${ }^{3}$ Danielsson, M, et al, European fournal of Cardiology.

anielsson, M, et al, European fournal of Cardiology.
In press.

\section{Aid to drug compliance}

SIR,-It is well known that patients, even when well motivated, often fail to take their prescribed drugs correctly. Obviously this is most likely to occur when aged patients are on multiple drugs; however, even a single course of an antibiotic may be taken incorrectly.

All drugs could be packed in "calendarpacks" with one tablet to be pushed out each marked day for four weeks and a space on each pack to mark, say, morning, noon, and evening. Then if the dose were two tablets thrice daily six such packs would give one month's supply. Some drugs are already available in this way-for example, contraceptive pills, certain iron preparations, Lasix $+K$, and Tenormin. Doubtless manufacturers are financially inhibited from changing to such packaging. However, in many countries it is already a legal requirement for drugs to be dispensed in an "original pack"; it would be possible for the Department of Health and Social Security to allow drug manufacturers to all increase in expenditure. This would result in a worthwhile increase in drug efficacy and safety.

A useful and simple interim measure would be to issue a small card with all medicines, inbe to issue a small card with all medicines, in-
cluding syrups and ointments. This would have retain extra profits to cover this once-and-for- 
the days of the week down one side and four columns alongside so that the appropriate square could be ticked when the dose was taken. This would provide patient and doctor with a handy visual check on drug compliance. On the back of the card could be printed details of any important side effects or contraindications.

\section{Michael KLABER} London Hospital, London E1

\section{Preventing infective endocarditis}

SIR,-Your leading article (17 December, $p$ 1564 ) is useful in drawing attention to the American Heart Association's latest recommendations ${ }^{1}$ on this important subject. It is perhaps regrettable that in Britain we have not managed to publish a similar report. ${ }^{2}$ Such a report was, in fact, prepared in mid-1975 and, largely owing to entrenched opinions, has not yet seen the light of day. In the preparation of this report I was in close communication with the American team, and the recommendations arrived at were virtually identical. I would, therefore, commend a study of the American Heart Association's full text to your readers.

Parenteral prophylaxis should be given in all patients with prosthetic valves and those treated in hospital. Your article mentions that the indications for an oral regimen are not clear. These were dealt with in my letter to the $B M Y$ in $1975^{2}$ and, in brief, arise from the fact that in this country in general dental practice, oral regimens are already widely used, that dentists will not give intramuscular injections to their patients, and liaison with the patient's doctor to permit injection to be given at the appropriate time is simply not practicable. Furthermore, the work of Pelletier et al suggests that a suitable oral regimen is efficiently bactericidal.

Because of the number of cases of infective endocarditis that do not follow a recognisable insult the importance of good conservative dental care cannot be too frequently stressed.

The suggestion in your final paragraph that "a modified technique might either confirm or qualify the conclusions drawn and possibly render the clinician's task less burdensome" seems to me to perpetuate the heavy weather that is made of this subject. Surely we have admirable recommendations before us and we should follow them until better are produced. In the light of present evidence they are "as harmless as possible, and as effective as possible."4

Hugh A Fleming

Addenbrooke's Hospital

Cambridge

${ }^{1}$ American Heart Association, Circulation, 1977, 56,

139A.
2 Fleming, H A, British Medical fournal, 1975, 2, 541. Pelletier, L L, Durack, D T, and Petersdorf, R G,

fournal of Clinical Investigation,

\section{Skateboard injuries}

SIR,-I was interested to note the distribution of injuries following skateboard accidents in Dr Cynthia Illingworth's article (24-31 December, p 1636).

Of particular note was the discovery of six fractures of the scaphoid out of 37 patients radiographed. Fractures of the scaphoid in children are very rare and if the incidence of scaphoid fractures in this small series is borne out by larger series it would seem extremely important for this to be brought to the notice of other people seeing skateboard injuries.

D W PILling

Sheffield

\section{Anorexia nervosa and family therapy}

SIR,-Your leading article on anorexia nervosa (7 January, p 5) gives fair mention of the importance of family factors. Many family therapists would want to emphasise the value of considering the family system-the "whole" which is more than the sum of the parts-and the significance of the blurring of the intergenerational boundary.

A family with an inadequate boundary between parents and children may present with symptomatology other than anorexia nervosa, but often where this condition is present the boundary problem seems to be especially relevant and striking. Therapy may be directed towards a strengthening of marita bonds and to a lessening of the emotional overinvolvement between child and parents. ${ }^{1}$

\section{Child Guidance Centre,}

Coventry

JAMES WARNER

Minuchin, S, Families and Family Therapy. London, Tavistock Publications, 1974.

\section{Cough in farmer's lung disease}

SIR,-Cough is an important diagnostic feature of farmer's lung disease (FLD). ${ }^{1}$ In most accounts, however, it is not stated whether the cough is dry or whether a significant amount of sputum is produced. Parratt et $a l^{2}$ and Grant et $a l,{ }^{3}$ for instance, use the dry cough as one criterion to select their cases of FLD. We think that the productivity of the cough is an important clinical element in the disease.

We have cultured specimens of sputum for the organisms associated with FLD since $1969^{4}$; the appearance (purulence, etc) of the sputum was also noted. From 1969 to 1977 80 isolations of Micropolyspora faeni and 25 isolations of Thermoactinomyces spp (mainly $T$ candidus $^{5}$ were made. Patients from whom these isolations were made all had clinical FLD; 35 patients $(50 \%)$ had copious sputum which was frequently purulent. Some of our patients appear to have had FLD for many years although they have avoided contact with mouldy hay. One patient has given up his farm and been a bus driver for the past two years but still produces positive sputum cultures.

We suggest that FLD can manifest itself in two ways, each with its symptomatology and serology. Firstly, FLD can appear as a mild acute illness, with symptoms which include a dry cough, that appears some hours after exposure to mouldy hay. The patients are serologically negative or weakly positive and thermoactinomycetes are not isolated from the sputum. But FLD can also appear insidiously as a chronic disabling disease with profuse purulent sputum and strongly positive serological findings; thermoactinomycetes can readily be isolated from the sputum. We suggest that the first manifestation of FLD is a "primary" sensitivity response and the latter disease process is the product of actual colonisation of the lung by thermoactinomycetes. Plate tests indicate tetracycline sensitivity of the thermoactinomycetes under study and it would seem to be logical to treat the chronic disease with tetracycline.

F BRIAN GREATOREX JOHN PETHER

Public Health Laboratory, Taunton and Somerset Hospital,

'Campbell, J M, British Medical fournal, 1932, 2, 1143 Parratt, D, et al, Clinical and Experimental Immunology,

Grant, I W B, et al, British Medical fournal, 1972, 1,

Pether, J V S, and Greatorex, F B, British fournal of Greatorex, F B, and Pether, JV S, Lancet, 1976, 1,
1134 .

\section{Campylobacter enteritis in Sweden}

SIR,-We read Dr M B Skirrow's report (2 July, p 9) with great interest and have adopted his technique for isolating campylobacteria from faeces. Between 15 July and 31 October we have isolated Campylobacter jejuni from 15 subjects (13 patients with diarrhoea and two healthy carriers). We can fully confirm previous observations on the severity of the diarrhoea in many cases-four of our patients had bloody stools. Agglutinating antibodies against formalinised suspensions of patients' strains have appeared in most cases.

Most of our patients (eight out of 13) have obviously been infected abroad (Finland, Spain, Great Britain, Tanzania) and in one case we have isolated $C$ jejuni from two members of the same family and also from the family dog, which also had an enteritis.

During the $3 \frac{1}{2}$ months 17 new cases of salmonellosis, five cases of shigellosis, and six cases of yersiniosis were diagnosed in our laboratory. Campylobacter thus seems to be as common a cause of diarrhoea in Sweden as any of the "established" pathogenic bacteria.

B LINDQUIST

J KJELLANDER T KOSUNEN

Departments of Clinical

Bacteriology and Paediatrics,

Regionsjukhuset,

Orrebro, Sweden

\section{Hair in the theatre}

SIR,-I was delighted to read $\operatorname{Dr} N$ A Simmons's letter on the flowing locks of the modern surgeon (14 January, p 111). To those of us old enough to remember the cropped heads of George Perkins and Philip Mitchiner these modern styles confirm what I have long suspected-that the Arbuthnot Lane technique of the '20s and ' 30 s which reduced sepsis in clean wounds to less than $1 \%$ has now been lost in an antibiotic euphoria. Recently I heard at a lecture one of the younger surgeons admitting to a sepsis rate of $8 \%$ in clean appendix wounds, and from talks with general practitioners who deal with patients discharged from hospitals there appears to be a real feeling of increasing sepsis in clean surgical wounds.

The surgeon's hair, of course, is probably only a minor factor in the problem, but if Dr Simmons's letter marks only the beginning 